\title{
An Alternative Strategy in Cancer Chemotherapy, Aimed Not at Killing Cancer Cells, but the Recovery of Their DNA, Modified by Active Oxygen
}

\author{
Yuri Pivovarenko \\ Research and Training 'Centre Physical and Chemical Materials Science' Under NAS of Ukraine, Kiev, Ukraine \\ Email address: \\ y.pivovarenko@gmail.com

\section{To cite this article:} \\ Yuri Pivovarenko. An Alternative Strategy in Cancer Chemotherapy, Aimed Not at Killing Cancer Cells, but the Recovery of Their DNA, \\ Modified by Active Oxygen. Biomedical Sciences. Vol. 3, No. 5, 2017, pp. 94-98. doi: 10.11648/j.bs.20170305.12
}

Received: August 17, 2017; Accepted: September 7, 2017; Published: October 10, 2017

\begin{abstract}
It is considered that the cause of some forms of cancer is the modification of DNA by active oxygen. This suggests that the removal of oxygen from the composition of such DNA will cure these forms of cancer. For the practical implementation of this idea proposed a number of substances that are harmless to humans, but have the ability to penetrate into cell nuclei and bind active oxygen.
\end{abstract}

Keywords: Reactive Oxygen Species, ROS, Cancer, Oncology

\section{Introduction}

There is a strong interest of oncologists to the active forms of oxygen (ROS). This interest stems from data showing that the number of cancers due to DNA modification by reactive oxygen species (ROS) [1-7].

It is important to note that oxygen is very easily attached to DNA: for example, this occurs when sparging of aqueous solutions of DNA with oxygen. It is also important that oxygen is very easily detaches from the DNA: for example, this occurs when degassing of aqueous solutions of DNA or sparging with nitrogen [8-11]. Thus, the relationship between oxygen and DNA damaged by reactive oxygen (for the sake of brevity, we will call it oxidized DNA), is weak. Given the low strength of such relationships, the removal of oxygen from the structure of oxidized DNA seems to be attractive. This allows us to offer an alternative approach to cancer chemotherapy, aimed not at killing the cancer cells with toxins, but to fix DNA damaged by active oxygen. Obviously, the most attractive in this aspect are substances which are harmless to humans.

\section{Material and Methods}

DNA, dTMP and dAMP were purchased from Fluka (Switzerland)

Other reactive were purchased from Ukrreachim
(Ukraine).

To fluorescence spectra recording Cary Eclipse fluorescence spectrofluorometer (Varian, Austria) was used.

\section{Results and Discussion}

\subsection{Oxidized DNA as a Donor of Active Oxygen}

Studying the fluorescence of porous silicon modified by aqueous solutions of oxidized DNA, we found that such a DNA is easy to oxidize porous silicon [12]. Checking the result, we found that oxidized DNA is a source of reactive atomic oxygen. This property of DNA can be demonstrated using the chemical reaction, which is usually used to determine the atomic oxygen $[13,14]$ :

$$
2 \mathrm{KI}+\mathrm{H}_{2} \mathrm{O}+\mathrm{O}^{*} \rightarrow \mathrm{I}_{2}+2 \mathrm{KOH}
$$

From equation (1) it is clear that the formation of one molecule of iodine is correlated with the formation of one atom of oxygen. Since the formation of molecular iodine during the reaction (1) can be observed visually that the oxidized DNA allocates atomic oxygen, it is possible to verify in any laboratory.

With this aim, $\sim 100$ micro liters of $0.1 \mathrm{M}$ aqueous solution of potassium iodide, in which was dissolved 1 micro gram of 
DNA, should be applied to the glass surface and dry this solution at room temperature.

As a result of such experiments, you can see that the drying drops acquire a brown color, which is due to the release of molecular iodine and increases over time (Figure 1).
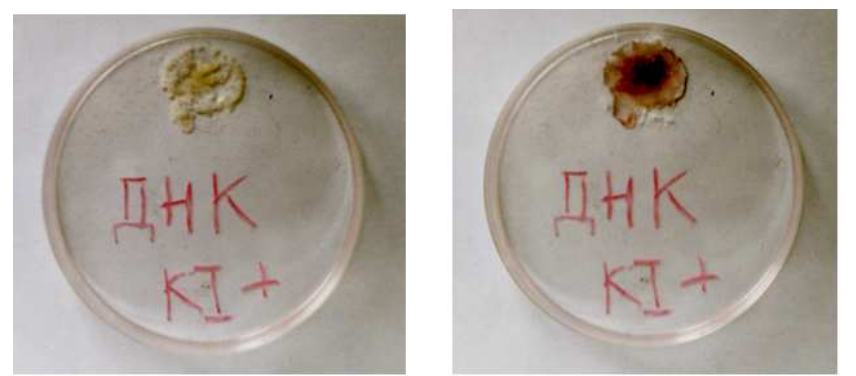

Figure 1. This Is a Drop of 0.1 M KI Solution Containing DNA, Immediately after Drying (Left) and after 24 Hours after Drying (Right). Drying Occurred at a Temperature of $20-22$ C. (ДНК Is DNA in Russian).

Given equation (1), this indicates the formation of molecular iodine and, therefore, the atomic oxygen. It is obvious that molecular iodine is formed from iodide of potassium, to be exact - of the iodide anions (1). Thus, given the previous results obtained in the study of the fluorescence of porous silicon [12], it can be argued that oxidized DNA is the source of atomic oxygen.

It can be also expect that the iodide anions can be acceptors of atomic oxygen, which is contained in the nuclear DNA. Of course, this can be expected, provided that the iodide anions enter the cell nucleus, so there is no confirmation.

\subsection{Chloride Anions as Potential Acceptors of Atomic Oxygen from Oxidized DNA}

It is known that the anion chloride are the most abundant anions of the human body and drinking water $[15,16]$. It is also known that chloride anions are easily attached to the oxygen atoms [13]:

$$
\mathrm{Cl}^{-}+\mathrm{O}^{*} \rightarrow \mathrm{ClO}-+\mathrm{O}^{*} \rightarrow \mathrm{ClO}_{2-}+\mathrm{O}^{*} \rightarrow \rightarrow \mathrm{ClO}_{3}{ }^{-}+\mathrm{O}^{*} \rightarrow \mathrm{ClO}_{4}^{-}
$$

Thanks to the combination of these properties, the chloride anions can also be considered as natural acceptors of oxygen atoms. But it may not be so, because all of the reaction products (2) easy to give oxygen [13]. In addition, the hypochlorite is one of the most active in biological systems [17].

That oxidized DNA still loses atomic oxygen in the presence of chloride anions can be seen by using spectral methods, because a characteristic feature of the oxidized DNA is the peak with a maximum at $260 \mathrm{~nm}$, which is detected in the UV absorption spectra of aqueous solutions of DNA [7-11]. It is known that this peak increases rapidly when modification of DNA by active oxygen and also decreases rapidly in the process of degassing or deoxygenating aqueous solutions pre-oxidized DNA [9-11]. Thus, the magnitude of this peak recorded in the UV absorption spectra of aqueous solutions of DNA can be used to determine the degree of oxidation of DNA.

Observing the changes A260 solutions of oxidized DNA that contain and do not contain chlorides, it is possible to make sure that A260 solutions that contain chlorides, gradually decreases, and A260 solutions that do not contain chlorides, is virtually unchanged for several days. Observing the changes A260 solutions of oxidized DNA that contain various chlorides can be sure that A260 solutions which contain calcium chloride, decreases most rapidly. Moreover, for such solutions is often observed complete disappearance of the peak with maximum at 260 nanometers. Obviously, these results clearly show that oxidized DNA gives atomic oxygen in the presence of chloride in its aqueous solutions.

This suggests that as the iodides and chlorides may be considered as a potential and safe reducing agents oxidized nuclear DNA. Of course, if these anions can penetrate into the cell nucleus of cancer cells.

\subsection{The Effect of $d A M P$ and dTMP on the Activity of Atomic Oxygen in Aqueous Solutions}

It can be expected that the problem of penetration into the nucleus of cancer cells may not be an issue for deoxynucleoside monophosphates, in particular, for dAMP, which can also be potential acceptors of atomic oxygen and take it from oxidized DNA. That dAMP is able to remove atomic oxygen from the oxidized DNA, was discovered in the study of the fluorescence of porous silicon modified by aqueous dAMP. In the study was convincing found that the dAMP water solutions are absolutely free from active oxygen [12]. Since the aqueous dAMP is easily oxidized by oxygen [15], this result was not surprising.

More unexpected were the properties of dTMP that can be seen as a kind of antagonist of dAMP. So, when studying the fluorescence of porous silicon modified with aqueous solutions of dTMP, it was found that the oxygen contained in such solutions, is sufficiently active to oxidize the porous silicon [12].

The fact that the influence of these substances on the activity of oxygen dissolved in aqueous solutions are significantly different, it's easy to visualize. Especially fast this can be done by using the working solution, which is a $0.1 \mathrm{M}$ solution of potassium iodide, to this is added 2-3 drops of $3 \%$ solution of hydrogen peroxide. After the addition of hydrogen peroxide resulting solution was pale yellow (Figure 2), due to the formation of molecular iodine, as in (1). 


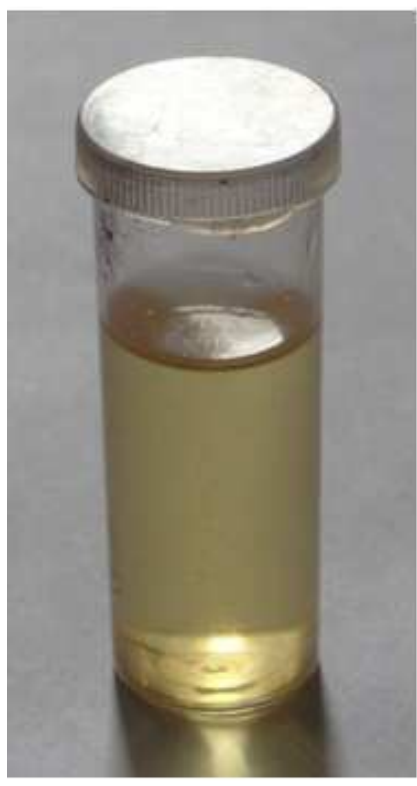

Figure 2. The Resulting Reaction Solution Containing Components of the Reaction Mixture, Which Are in Dynamic Equilibrium: $2 \mathrm{KI}+\mathrm{H}_{2} \mathrm{O}_{2}\left(\mathrm{H}_{2} \mathrm{O}+\right.$ $\left.\mathrm{O}^{*}\right) \leftrightarrow I_{2}+2 \mathrm{KOH}$. The Reaction Solution is Initially Slightly Yellow.

It is considered that, after adding hydrogen peroxide, the working solution contains the reaction mixture components are in dynamic equilibrium [13]:

$$
2 \mathrm{KI}+\mathrm{H}_{2} \mathrm{O}_{2}\left(\mathrm{H}_{2} \mathrm{O}+\mathrm{O}^{*}\right) \leftrightarrow \mathrm{I}_{2}+2 \mathrm{KOH}
$$

To the obtained solution was added a few crystals $(\sim 1 \mathrm{mg})$ of the analyzed substances, dAMP and dTMP. A noticeable difference could be observed in $\sim 30$ minutes (Figure 3). Thus, it is found that the reaction solution, being initially slightly yellow, in $\sim 30$ minutes became brown in the presence of a few crystals of dTMP (Figure 3, left), whereas it became colorless in the presence of dAMP (Figure 3, right).

Given equation (1'), it can be concluded that in the presence of dTMP increases the amount of atomic oxygen in the aquatic environment:

$$
2 \mathrm{KI}+\mathrm{H}_{2} \mathrm{O}_{2} \rightarrow \mathrm{I}_{2}+2 \mathrm{KOH}[13]
$$

Also, given equation $\left(1^{\prime}\right)$, it can be concluded that in the presence of dAMP reduces the amount of atomic oxygen in the aquatic environment:

$$
\mathrm{I}_{2}+2 \mathrm{KOH} \rightarrow 2 \mathrm{KI}+\mathrm{H}_{2} \mathrm{O}_{2}\left(\mathrm{H}_{2} \mathrm{O}+\mathrm{O} * \uparrow\right)[13]
$$

Considering the obtained result (Figure 3, right) and the results obtained from the study of fluorescence of porous silicon modified with aqueous solutions of dAMP [12], it can be concluded that the aqueous solutions do not contain active oxygen. Given that dAMP is a natural component of karyoplasms, it can be offered as a means of liberation of karyoplasms from active oxygen, i.e. as a potential and safe means of chemotherapy for those cancers that are caused by oxidation of DNA. This, again, may be if dAMP can get into the cell nucleus.

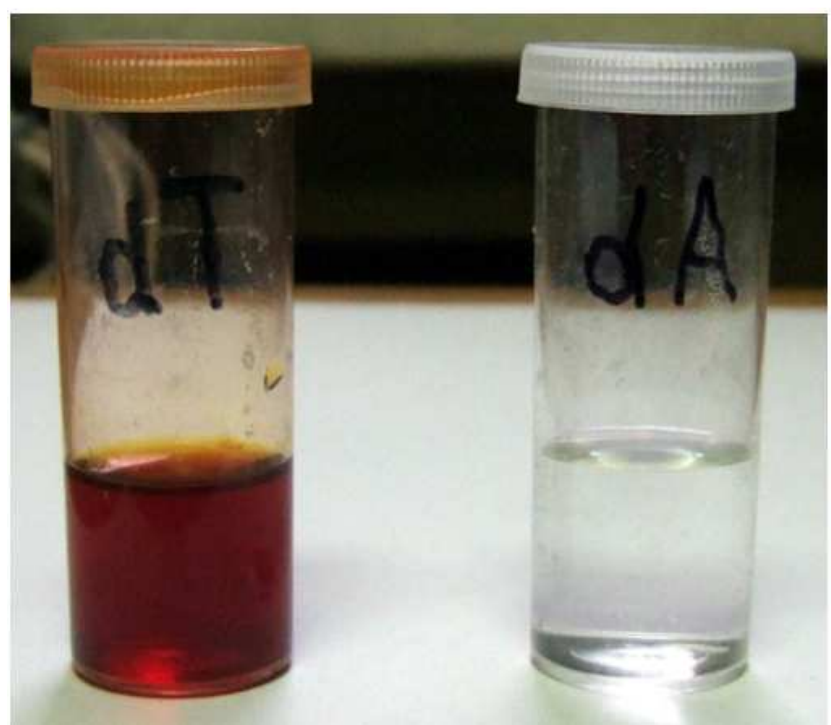

Figure 3. The Solution Containing the Reaction Mixture: $2 \mathrm{KI}+\mathrm{H}_{2} \mathrm{O}_{2}\left(\mathrm{H}_{2} \mathrm{O}\right.$ $\left.\left.+\mathrm{O}^{*}\right) \leftrightarrow I_{2}+2 \mathrm{KOH}\right)$, Was Originally Pale Yellow, in $\sim 30$ Minutes Became Brown in the Presence of a Few Crystals of TMP (Left), Whereas it Became Colourless in the Presence of a Few Crystals of dAMP (Right).

\subsection{Gaseous Hydrogen as a Potential Reductant of Oxidized DNA}

The problem of hitting the cell nucleus is absent for gaseous hydrogen, with the anomalous penetration. To verify that the anomalous penetration of gaseous hydrogen, it is enough to observe a plastic bottle filled it with hydrogen gas (Figure 4).

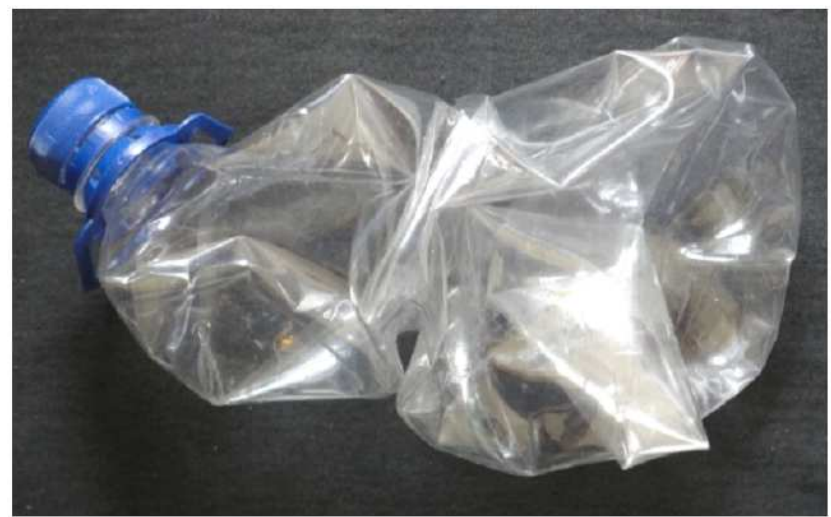

Figure 4. This Is a Closed Polyethylene Bottle with Hydrogen Gas after 2 Weeks of Filling. The Changes Show that Hydrogen Gas Can Easily Permeate Through the Polyethylene.

Because hydrogen not only has high penetrating power, but is an active reducing agent [13], it can penetrate into the cell nucleus and react with atomic oxygen:

$$
\mathrm{H}_{2}+\mathrm{O}^{*} \rightarrow \mathrm{H}_{2} \mathrm{O}
$$

A natural source of hydrogen gas is a normal intestinal micro flora. Thanks to its activity, the proportion of hydrogen in the composition of human intestinal gas is from 20 to $37 \%$ (vol.) [19]. Thus, influencing the composition and activity of the intestinal micro flora, it is possible to control the 
generation of intestinal hydrogen.

Also as a therapeutic tool, you can use water that is saturated with gaseous hydrogen. In favor of this proposal indicates the disappearance of the described peak with maximum at 260 nanometers on the UV absorption spectra of aqueous solutions of DNA, which occurs after bubbling gaseous hydrogen.

It is very convenient to obtain such water, ensuring its contact with metallic magnesium [13]:

$$
\mathrm{Mg}+\mathrm{H}_{2} \mathrm{O} \rightarrow \mathrm{Mg}(\mathrm{OH})_{2}+\mathrm{H}_{2} \uparrow
$$

Saturation of water with gaseous hydrogen conveniently evaluated by fluorescence at a wavelength of 410, 2 nanometers (Figures 5, 6). It may be important that this maximum in fluorescence spectra is situated close to the wavelength of violet spectral lines of hydrogen gas emission $(\sim 410,17 \mathrm{~nm})$ of the Balmier series [20,21].

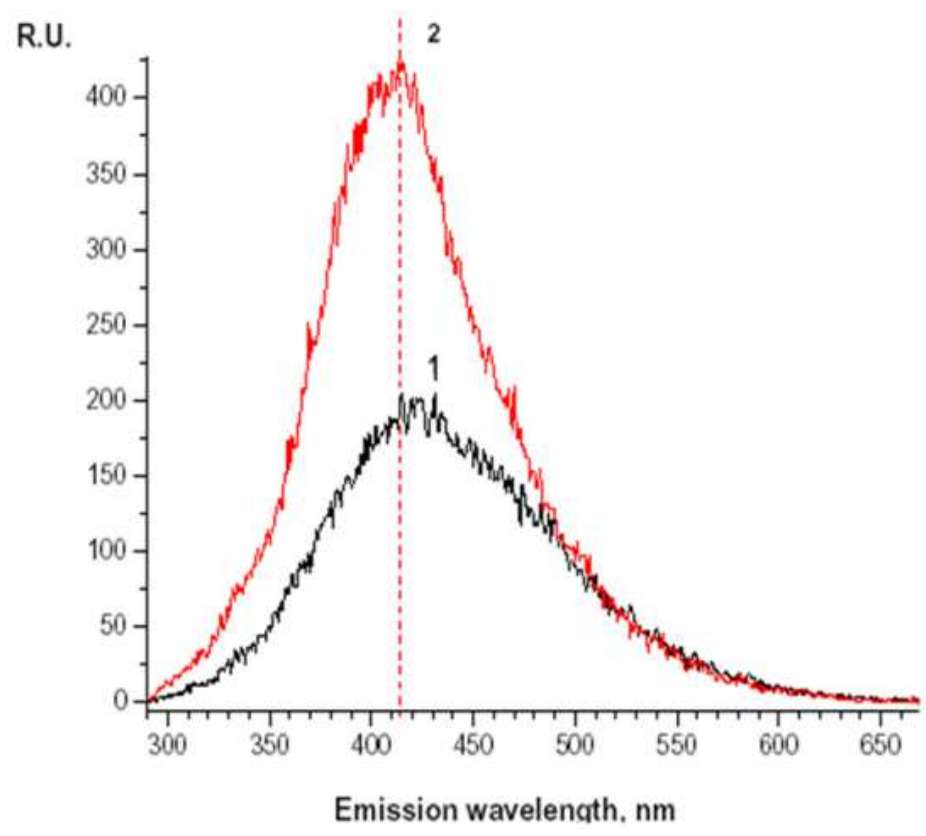

Figure 5. This Is Spectra Fluorescence Spectra of Distilled Water (1) and Distilled Water Saturated with Hydrogen Gas (2).

The primary fluorescence excitation wavelength was $260 \mathrm{~nm}$ [22]. All investigated solutions were at room temperature.

R.U.

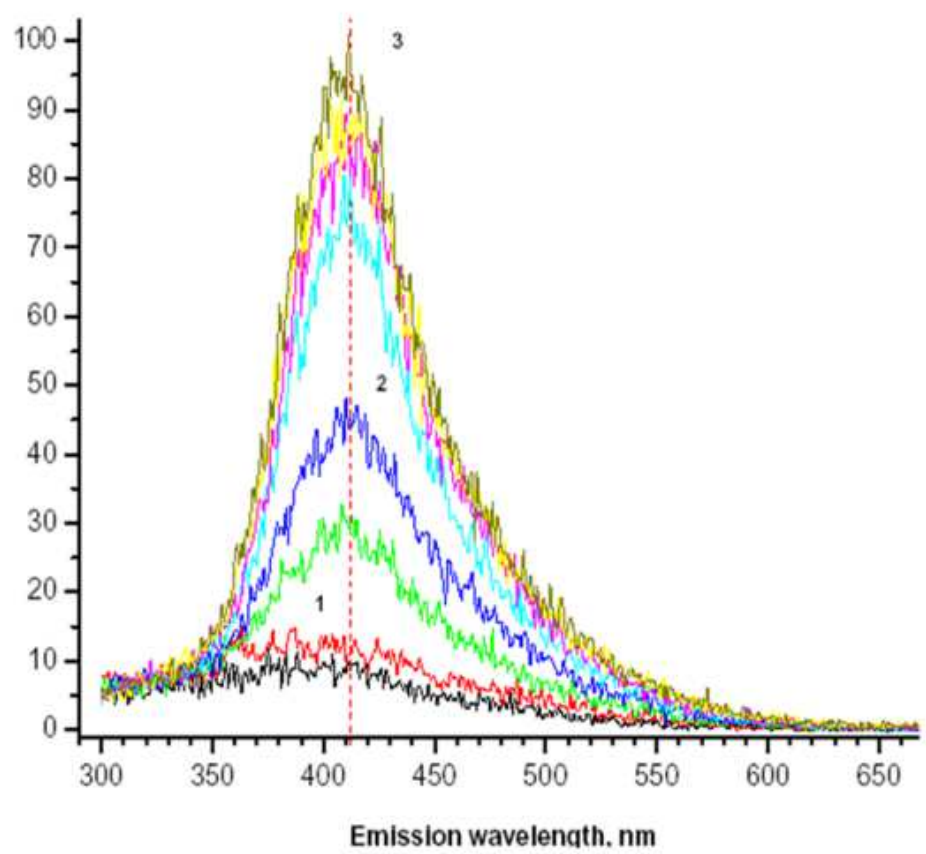

Figure 6. This is Spectra Fluorescence Spectra of Aqueous Solution Containing Reaction Products of Magnesium Metal and Water: 1 - before the Reaction; 2 - 15 Min after the Start of the Reaction; 3 - 30 Min after the Start of the Reaction. 
The primary fluorescence excitation wavelength was 260 $\mathrm{nm}[22]$. All investigated solutions were at room temperature.

\section{Conclusion}

Oxidized DNA can easily split atomic oxygen. This allows us to offer a number of harmless ways to remove atomic oxygen from DNA, as well as from its environment.

\section{References}

[1] Frenkel, K. (1992) Carcinogen-mediated oxidant formation and oxidative DNA damage. Pharmacol. Ther., 53, 127-166.

[2] Poulsen H. E., Prieme H., and Loft S. (1998) Role of oxidative DNA damage in cancer initiation and promotion. Eur. J. Cancer Prev., 7(1), 9-16.

[3] Bandyopadhyay U., Das D. and Banerjee R. K. (1999) Reactive oxygen species: Oxidative damage and pathogenesis. Current Science, 77(5), 658-666.

[4] Cooke M. S., Evans M. D., Dizdaroglu M., and Linec J. (2003) Oxidative DNA damage: mechanisms, mutation, and disease. FASEB J., 17(10), 1195-1214.

[5] Khan F. and Ali R. (2005) Enhanced recognition of hydroxyl radical modified plasmid DNA by circulating cancer antibodies. J. Exp. Clin. Cancer Res., 24, 289-296.

[6] Khan Fozia, Khan Farina and Ali R. (2007) Immunogenicity of DNA damaged by singlet oxygen: Implications in SLE and Cancer. Biotechnology and Applied Biochemistry, 46(2), 97103.

[7] Terentyeva Y. and Pivovarenko Y. (2015) UV absorbance of lymfocytes. European Journal of Advanced Research in Biological and Life Sinces, 3(4), 20-24.

[8] Khan Fozia, Khan Farina, Siddicu A. A. and Ali R. (2006) Enhancement of immunogenicity of plasmid DNA under the action of singlet oxygen. Biochemistry (Russian edition), 71(8), 1074-1082.

[9] Doshi R., Day P. J. R. and Tirelli N. (2009) Dissolved oxygen alteration of the spectrophotometric analysis and quantification of nucleic acid solutions. Biochem. Soc. Transactions, 37, 466-470.
[10] Doshi R., Day P. J. R., Carampin P., Blanch E., Statford I. J. and Tirelli N. (2010) Spectrophotometric analysis of nucleic acids: oxygenation-dependant hyperchromism of DNA. Anal. Bioanal. Chem., 396, 2331-2339.

[11] Pivovarenko, Y. V. (2014) Hypochromism degassed solutions of DNA Modern high technologies. 3, 147-150 (in Russian).

[12] Shevchenko V. B., Datsenko A. I., Shablikin O. V., Osadchuk T. V., Lyakhov A. M., Pivovarenko Y. V. and Makara V. A. (2012) Definition of ROS in the presence of biologically active substances by porous silicon fluorescence. Ukrainian Biochemical Journal, 84(4), 67-7 (in Ukrainian).

[13] Nekrasov B. V. (1974) Bases general chemistry, 1. Moscow: Chemistry (In Russian).

[14] Peregud E. A. and Gernet E. B. (1973) Air Chemical Analysis of Industrial Plants. Leningrad: Chemistry (in Russian).

[15] Wesson L. G. (1969) Physiology of the human kidney. New York: Grune and Stratton, 1.

[16] Fadeeva V. K. (1971) Effect of drinking water with different chloride contents on experimental animals. Hygiene and sanitation, 36(6), 111-115 (in Russian).

[17] Vladimirov Yu. A. (2004) Active forms of oxygen and nitrogen: implications for diagnosis, prevention and therapy. Biochemistry (Russian Ed.), 69(1), 5-7.

[18] Shabarova Z. A., and Bogdanov, A. A. (1978) Chemistry of nucleic acids and their components. Moscow: Chemistry (In Russian).

[19] Harchenko, N. V., Tchernenko, V. V., Tchervak, I. N., Stukalo, V. M., Tokar, D. V. (2008) Using Espumizan preparation in practice gastroenterologist. Ukraine's Health, 6(1), 52-53 (in Ukrainian).

[20] Shpolsky E. V. (1974) Atomic Physics, 1. Moscow: Nauka.

[21] Kuchling H. (1980) Physik. Leipzig: VEB Fachbuchverlag.

[22] Belovolova, L. V.; Glushkov, M. V.; Vinogradova, G. I., (2006) Features water fluorescence activated electrolysis. The role of reactive oxygen species. Electronic multidisciplinary scientific journal "Investigated in Russia" of Moscow PhysicTechnical Institute, 268, 2588-2601. Available from: http://zhurnal.ape.relarn.ru/articles/2006/268.pdf. [Accessed: 24th March 2012] (In Russian). 